\title{
EDUCAÇÃO SEXUAL NA BAHIA NAS PRIMEIRAS DÉCADAS DO SÉCULO XX
}

\author{
Tereza Cristina Pereira Carvalho Fagundes'
}

CRUZ, Izaura Santiago da. Educação Sexual na Bahia nas primeiras décadas do Século XX. 2017. 183 p. (Tese de Doutorado). Programa de Pós-Graduação em Ensino, Filosofia e História das Ciências. Universidade Federal da Bahia/Universidade Estadual de Feira de Santana, 2017.

A tese de doutorado da pesquisadora docente da Universidade Federal da Bahia Izaura Santiago da Cruz, intitulada "Educação Sexual na Bahia nas primeiras décadas do Século XX", apresentada ao Programa de Pós-Graduação em Ensino, Filosofia e História das Ciências / UFBA / UEFS teve como objetivo

Analisar ideias difundidas em teses de medicina e manuais sobre educação sexual na Bahia no início do século XX (1900 a 1940) buscando situá-las no contexto da educação mais geral da época, na Bahia e no Brasil.

Trata-se de um importante estudo no campo da História das Ciências, em especial, da História da Educação Sexual, organizado em quatro capítulos: 1. Sexo, sexualidade e educação sexual - ideias fundamentais; 2. Raul Brandão - Educação Sexual, moralidade e família: uma resposta às "ameaças" do feminismo; 3. Ítala Silva de Oliveira: da Sexualidade à Educação Sexual; e 4. A defesa da educação sexual: a proliferação de discursos sobre a sexualidade, se materializando através de textos sobre Educação Sexual.

$\mathrm{Na}$ introdução da tese a pesquisadora declara que sua aproximação ao tema da Educação Sexual decorreu de sua trajetória profissional, iniciada como professora de ciências (da alfabetização ao ensino médio) até a docência universitária em que atua, principalmente, no campo da formação de professoras e professores de ciências. A trajetória da pesquisa é apresentada nessa introdução, pontuando as descobertas que direcionaram o percurso do estudo, coleta e análise dos dados.
Ideias basilares sobre sexo, sexualidade e educação sexual são apresentadas no Capítulo 1 , em que a autora, partindo do pensamento de Charles Darwin em torno desses conceitos até chegar aos discursos de médicos europeus presentes no meio acadêmico da Bahia na Primeira República, destaca de forma analítica e crítica os estudos de Paolo Mantegazza, Antônio Caetano D'Abreu Freire Egas-Moniz e Sigmund Freud.

Os escritos de Paulo Mantegazza, médico italiano, ressaltam concepções inovadoras para a época sobre sexo e sexualidade desvinculados das questões morais e pensamento religioso predominantes e definem a arte de escolher parceiros num casamento, a fisiologia do amor e do prazer, a fisiologia feminina, os papéis de gênero no casamento e a arte de ser feliz. Egas-Muniz, mundialmente conhecido pelos seus estudos sobre neurologia, psiquiatria e sexualidade, tem analisado em seus estudos as transformações do corpo da mulher e do homem na puberdade, vida sexual, masculinidades e feminilidades do ponto de vista eminentemente orgânico e suas reflexões específicas para colegas médicos sobre neuroses sexuais, assexualidade, homossexualidades, heterossexualidade mórbida, perversões sexuais e vida sexual de alienados. A análise dos ensaios sobre sexualidade e outros estudos de Freud bem como uma contextualização histórica e social na qual emerge o campo da educação sexual no Brasil culminam o capítulo. Em que pese a opção da autora por uma menor ênfase ao pensamento de Freud sobre a temática, ressalta-se que sua abordagem atende à exigência acadêmica de se perpassar pelo discurso de Freud qualquer abordagem sobre sexualidade humana que se queira proceder. Assim, a autora não deixa de destacar a

${ }^{1}$ Pedagoga, Mestra e Doutora em Educação pela Universidade Federal da Bahia (UFBA). Professora Adjunta Aposentada (UFBA). Associada e Delegada Regional da Sociedade Brasileira de Estudos em Sexualidade Humana (SBRASH). Membro da Comissão Editorial da Revista Brasileira de Sexualidade Humana (RBSH). E-mail: tcrispf@uol.com.br. 
importância dos estudos freudianos para a compreensão e a difusão do pensamento acadêmico baiano sobre a temática, que mais tarde, segundo ela, contribuiria certamente para a construção de um arcabouço teórico subjacente a programas de educação sexual nas décadas seguintes.

No capítulo 2, sobre Paulo Mendes de Castilho Brandão, a ênfase recai na percepção desse autor sobre educação sexual dada pela família, a divisão de papéis entre os pais na criação dos filhos. Trata, também, de questões como a precocidade sexual, moléstias sexuais e formação sexual de moças e rapazes com vistas ao casamento. Brandão critica veementemente o movimento feminista da época, defendendo o estabelecimento e a manutenção dos papéis femininos tradicionais. Critica, também, a homossexualidade, indicando a educação sexual para combater esta conduta.

Os capítulos 3 e 4 particularizam as concepções da médica alagoana Ítala da Silveira, formada pela Faculdade de Medicina da Bahia na década de 1920. Inovadora, essa médica dedica uma seção de sua tese à defesa do feminismo e à ideia de coeducação (convivência de moças e rapazes na mesma escola), estuda a fisiologia sexual feminina e defende a educação sexual como parte da educação global desde a infância até a velhice. São pontos fundamentais da educação sexual prevista por Ítala da Silveira: o entendimento de que a instrução feminina possibilita a existência de um modelo de relacionamento entre casais calcado no companheirismo e compartilhamento de responsabilidades, a equivalência de mulheres e homens no campo do Direito e a educação sexual para a juventude com vistas à eliminação de preconceitos e controle do instinto sexual, a prática da higiene e o preparo para a maturidade e o casamento, para a equidade e para o respeito entre homens e mulheres, entre outros aspectos. Nesse ponto, a autora deixa de identificar o pensamento de Ítala da Silveira com a primeira onda do feminismo, que visava não apenas conquistar os direitos civis e políticos das mulheres, mas que elas alcançassem a condição de sujeito. Seria preciso, no entanto, destacar que essa primeira onda feminista não superava o essencialismo relacionado à condição feminina. Também é importante destacar que se tratava de um movimento formado, principalmente, por mulheres brancas e de classe média, excluindo negras e operárias, que ocupavam outros espaços e eram ignoradas pelas próprias feministas da época.

Uma importante contribuição da tese de
Izaura Santiago da Cruz é a sistematização do pensamento científico sobre sexualidade na Bahia nos primeiros anos do século $X X$, culminando com uma "Proposta de Educação Sexual" a partir das proposições da médica em diálogo com as posições de outros autores da época estabelecendo um quadro das principais ideias sobre Educação Sexual compartilhadas e difundidas naquele período. Seria muito pertinente analisar que ideias e prescrições construídas naquele contexto ainda se encontram em projetos atuais de Educação Sexual, numa sociedade cada vez mais conservadora, em alguns aspectos, em que pesem os avanços notórios no campo científico dedicado à exploração e análise dos fenômenos biopsicossociais inerentes à manifestação da sexualidade.

A tese culmina com as Considerações Finais em que a autora referenda as significativas contribuições da perspectiva feminista de Ítala da Silveira, no início do Século XX, para transformações sociais das relações entre os gêneros e, consequentemente, para vivências mais satisfatórias e plurais da sexualidade humana.

A tese de Izaura Santiago da Cruz testemunha a importância da História da Ciência para a construção do conhecimento, na medida em que revela a intrincada rede de processos próprios do campo científico, processos esses que se caracterizam por relações de poder e redes de influência, destacando-se assim a profunda inserção da ciência em seu contexto sócio/histórico/cultural.

Izaura Santiago da Cruz - Graduada em Ciências Biológicas pela Universidade Federal do Pará. Especialista em Sexualidade Humana pela Universidade Estácio de Sá(RJ). Mestra e doutora em Ensino Filosofia e História das Ciências pela Universidade Federal da Bahia/Universidade Estadual de Feira de Santana. Professora Adjunta da Universidade Federal da Bahia. Lattes: http://buscatextual.cnpq.br/buscatextual/visualizacv.do? $\mathrm{id}=\mathrm{K} 4594141 \mathrm{P} 6$ e-mail: izaura.cruz@gmail.com 